\title{
Synthesis and bacterial biofilm inhibition studies of ethyl $N$-(2-phenethyl) carbamate derivatives $\uparrow$
}

\author{
Steven A. Rogers, Daniel C. Whitehead, Trey Mullikin and Christian Melander*
}

\author{
Received 29th April 2010, Accepted 9th June 2010 \\ First published as an Advance Article on the web 8th July 2010 \\ DOI: 10.1039/c0ob00063a
}

An 88 member library based upon the marine bacterial metabolite ethyl $N$-(2-phenethyl) carbamate was evaluated for bacterial biofilm inhibition against a panel of medically relevant strains. These studies culminated in the discovery of a new class of molecules capable of inhibiting the formation of $S$. aureus biofilms with low micromolar $\mathrm{IC}_{50}$ values.

\section{Introduction}

Bacterial biofilms are defined as surface-adhered communities of bacteria encased in an extracellular matrix of biomolecules. ${ }^{1}$ This particular phenotype of bacterial growth is incredibly resilient to conventional antibiotics, antiseptics, and host defences. ${ }^{2}$ In fact, biofilms of medically relevant bacteria constitute more than $80 \%$ of all bacterial infections. ${ }^{3}$ Additionally, biofilms have been implicated in the persistence of infections of indwelling medical devices, ${ }^{4}$ and are responsible for the mortality and morbidity of all cystic fibrosis $(\mathrm{CF})$ patients. ${ }^{5}$

Despite the preponderance of severe medical conditions that are influenced by bacterial biofilms, there exists a relative dearth of small, drug-like molecular scaffolds that affect their formation and maintenance. ${ }^{6}$ Examples of various compound classes known to possess anti-biofilm activity include homoserine lactone derivatives, ${ }^{7}$ brominated furanones, ${ }^{8}$ and ursine triterpenes. ${ }^{9}$ Additionally, high throughput screening approaches ${ }^{10}$ and computer aided drug design methods ${ }^{11}$ have also resulted in the discovery of a few novel scaffolds that possess anti-biofilm activity.

Our group has had marked success in the development of novel molecular scaffolds that can both inhibit and disperse bacterial biofilms across order, class, and phylum. Our unifying strategy towards the development of these molecules has been through the systematic design and optimization of structural motifs embedded within the core structure of the marine natural product bromoageliferin. ${ }^{12}$

With the aim of introducing a new class of molecules possessing potent anti-biofilm activity, we sought to evaluate a library of analogues based upon the bacterial metabolite ethyl $N$-(2phenethyl) carbamate (2d), isolated from the marine bacteria SCRC3P79 (Cytophaga $\mathrm{sp}$.). ${ }^{13}$ A. Yamada et al. reported that 2d exhibited moderate antibiofilm activity against the marine $\alpha$-proteobacteria Rhodospirillum salexigens. Yamada performed preliminary analogue synthesis by varying the aromatic appendage with substituted benzene rings and the ethyl appendage with a

Department of Chemistry, North Carolina State University, 2620 Yarbrough Dr.,Raleigh, NC, 27695-8204, USA. E-mail: christian_melander@ ncsu.edu; Fax: + 1 919-515-5079; Tel: +1 919-513-2960

$\dagger$ Electronic supplementary information (ESI) available: Experimental details for synthesis and biology and analytical data for all compounds. See DOI: $10.1039 / \mathrm{c0}$ ob00063a handful of aliphatic subunits. None of the analogues demonstrated improved activity in comparison to $\mathbf{2 d} .^{13}$ Based on these results and our success with 2-AI derivatives, we raised the question as to whether or not this metabolite (2d) would display anti-biofilm properties against more medically relevant bacteria. Furthermore, if this was the case and compound $\mathbf{2 d}$ was active against medically relevant bacteria, would the synthesis and screening of a more structurally diverse library of $\mathbf{2 d}$ analogues provide potent antibiofilm compounds? We were particularly eager to investigate a library of analogues based on $\mathbf{2 d}$, due to their relative structural simplicity and ease of synthesis and purification as compared to our 2-aminoimidazole-based modulators. Presented herein is an account of the results of this pilot study.

\section{Results and discussion}

Ethyl $N$-(2-phenethyl) carbamate 2d was synthesized from commercially available materials by routine acylation methodology (ethyl chloroformate/TEA in DCM) (Scheme 1). Compound 2d was isolated in $96 \%$ yield without recourse to chromatographic purification.

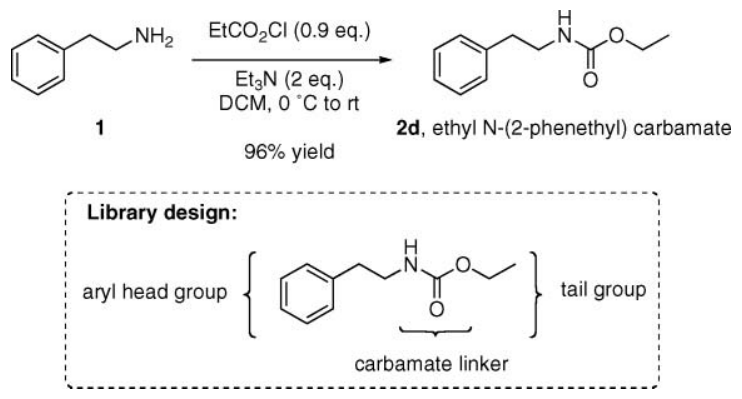

Scheme 1 Preparation of metabolite $2 \mathbf{d}$ and library design.

Similar to Yamada et al., we found that $\mathbf{2 d}$ displayed mediocre antibiofilm activity against $R$. salexigens, giving a $59.7 \%$ inhibition at a $200 \mu \mathrm{M}$ concentration as judged by a crystal violet reporter assay. ${ }^{14}$ Interestingly, a $200 \mu \mathrm{M}$ concentration of 2d also displayed activities against various medically relevant bacterial strains, inhibiting $63.1 \%, 68.1 \%, 80.2 \%, 52.0 \%$ and $40.8 \%$ of biofilm formation for $S$. epidermidis, methicillin-resistant $S$. aureus (MRSA), vancomycin-resistant Enterococcus faecium (VRE), multi-drug resistant Acinetobacter baumannii (MDRAB), and $E$. coli respectively (Table 1).

After successfully obtaining antibiofilm activity for $\mathbf{2 d}$ against medically relevant bacteria, a three part structure-activity analysis was designed (see Scheme 1), which entailed a systematic modulation of the metabolite's aromatic head region, carbamate linkage, and tail group. 
Table 1 Biofilm inhibition activity of $\mathbf{2 d}$ against various bacteria

\begin{tabular}{ll}
\hline Strain & $\%$ Inhibition $(200 \mu \mathrm{M} 2 \mathrm{~d})$ \\
\hline S. epidermidis & 63.1 \\
MRSA & 68.1 \\
VRE & 80.2 \\
R. salexigens & 59.7 \\
MDRAB & 52.0 \\
E. coli & 40.8 \\
\hline
\end{tabular}

The natural product analogues were synthesized using the same method used to prepare 2d. Specifically, the respective amine was reacted with 0.9 equivalents of the requisite chloroformate, isocyanate, dicarbonate, or isothiocyanate in the presence of 2.0 equivalents of triethylamine in dichloromethane (see ESI for details $\dagger$ ). Each of the listed amines was reacted independently with each acylating reagent to produce an 88 member pilot library in yields ranging from $76-98 \%$. Various aromatic head groups were used, incorporating the indole, triazole, indane, tetrahydroquinoline, indoline, and pyridine, as well as para-amino, paramethoxy, and para-bromo substituted phenyl rings. The carbamate heteroatomic core was varied through the substitution with a thiocarbamate, urea, and thiourea linkages. Tail modifications were made through the incorporation of the (-)-menthyl, benzyl, $t$-butyl and cholesteryl groups (Scheme 2).

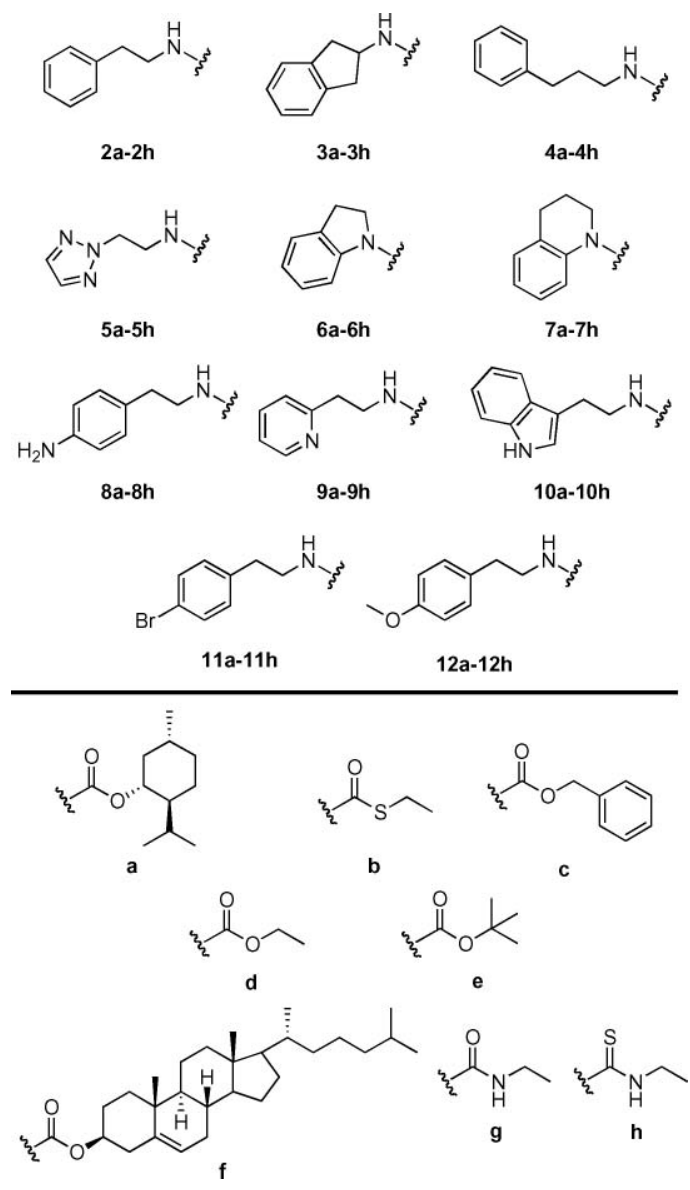

Scheme 2 Analogue library.

Once 2a-12h had been synthesized, they were screened for their ability to inhibit biofilm formation of S. epidermidis, MRSA, VRE,
Table 2 Biofilm inhibition $\left(\mathrm{IC}_{50}\right)$ against MRSA and E. coli

\begin{tabular}{lll}
\hline Compound & ${\text { MRSA } \mathrm{IC}_{50} / \mu \mathrm{M}}$ & E. coli $\mathrm{IC}_{50} / \mu \mathrm{M}$ \\
\hline $5 \mathrm{a}$ & - & 28.3 \\
$8 \mathrm{a}$ & 49.8 & $\overline{34}$ \\
$9 \mathrm{a}$ & 4.87 & $\overline{66}$ \\
$10 \mathrm{a}$ & 4.70 & 66.4 \\
$10 \mathrm{c}$ & - & \\
\hline
\end{tabular}

R. salexigens, MDRAB and E. coli at a $200 \mu \mathrm{M}$ concentration. None of the compounds displayed notable antibiofilm activity against $S$. epidermidis, VRE, $R$. salexigens, or MDRAB. Nevertheless, compounds $\mathbf{4 c}, \mathbf{8 a}, \mathbf{9 a}$, and $\mathbf{1 0 a}$ displayed greater than $90 \%$ inhibition of MRSA biofilms at $200 \mu \mathrm{M}$ concentration. Furthermore, compounds 5a, 9a, and 10c exhibited greater than $80 \%$ inhibition of $E$. coli biofilms at $200 \mu \mathrm{M}$ concentration.

Dose-response curves were generated for the lead compounds for the inhibition of MRSA and E. coli biofilms (Table 2). Non-bactericidal antibiofilm activity was verified through colony count analysis of the planktonic viability in the presence and in the absence of each compound at their $\mathrm{IC}_{50}$ value (i.e. the concentration that inhibits $50 \%$ of biofilm formation, see ESI for details $\dagger$ ). Against MRSA, $\mathrm{IC}_{50}$ values were determined to be $49.8 \mu \mathrm{M}, 4.87 \mu \mathrm{M}$ and $4.70 \mu \mathrm{M}$ for $\mathbf{8 a}, \mathbf{9 a}$, and 10a respectively. Against E. coli, $\mathrm{IC}_{50}$ values were determined to be $28.3 \mu \mathrm{M}$, $34.6 \mu \mathrm{M}$ and $66.4 \mu \mathrm{M}$ for $\mathbf{5 a}, \mathbf{9 a}$, and $\mathbf{1 0 c}$ respectively.

Given the potency of our lead compounds toward inhibiting MRSA biofilms, we next explored their activity against various other $S$. aureus strains. Specifically, we screened 8a, 9a, and 10a against three additional $S$. aureus strains (ATCC \#'s 29213, 29740, and 25923). $\mathrm{IC}_{50}$ values were determined for each compound against each of the $S$. aureus strains; in some cases, the compounds were found to be more potent than they were against MRSA.

$\mathrm{IC}_{50}$ values for compound $\mathbf{8 a}$ were found to be $21.2 \mu \mathrm{M}, 24.3 \mu \mathrm{M}$ and $71.9 \mu \mathrm{M}$ against 29213, 29740 and 25923 respectively. For 9a they were found to be $124 \mu \mathrm{M}, 82.2 \mu \mathrm{M}$ and $19.7 \mu \mathrm{M}$ for 29213 , 29740 and 25923 respectively. Lastly, for compound 10a, which was found to be the most active compound overall, $\mathrm{IC}_{50}$ values were determined to be $4.70 \mu \mathrm{M}, 2.84 \mu \mathrm{M}$ and $37.4 \mu \mathrm{M}$ for 29213 , 29740 and 25923 respectively (Table 3). Again, planktonic viability in the presence of the test compounds was verified through colony count analysis.

Interestingly, our most potent inhibitors of the S. aureus strains including MRSA contained (-)-menthyl carbamates. Indeed, (-)menthol and its derivatives have long been shown to have various antimicrobial and antiplasmid effects on bacteria. ${ }^{15}$ Along with (-)-menthol (13), the related natural products thymol (14) and carvacrol (15) (Scheme 3, dashed box) are also known to possess antimicrobial activity. ${ }^{16}$ In light of this observation, we prepared the thymyl and carvacryl carbamate analogues of 9a and 10a. We chose these two compounds for analogue design because they had the lowest $\mathrm{IC}_{50}$ values against MRSA and both worked well against 29213, 29740, and 25923 (see Tables 2 and 3). Additionally, we prepared the stereochemical antipodes of $9 \mathbf{a}$ and 10a by employing (+)-menthyl carbamate. Finally, we prepared the cyclohexyl carbamate derivatives of $\mathbf{9 a}$ and $\mathbf{1 0 a}$ as a control (Scheme 3).

With compounds $\mathbf{9 i - 1 0 l}$ in hand, they were then screened for biofilm inhibition activity along with (-)-menthol and 
Table 3 Biofilm inhibition $\left(\mathrm{IC}_{50}\right)$ against other $S$. aureus strains

\begin{tabular}{llll}
\hline Compound & $29213 \mathrm{IC}_{50} / \mu \mathrm{M}$ & $29740 \mathrm{IC}_{50} / \mu \mathrm{M}$ & $25923 \mathrm{IC}_{50} / \mu \mathrm{M}$ \\
\hline $8 \mathrm{a}$ & 21.2 & 24.3 & 71.9 \\
$9 \mathrm{a}$ & 124 & 82.2 & 19.7 \\
$10 \mathrm{a}$ & 4.70 & 2.84 & 37.4 \\
\hline
\end{tabular}

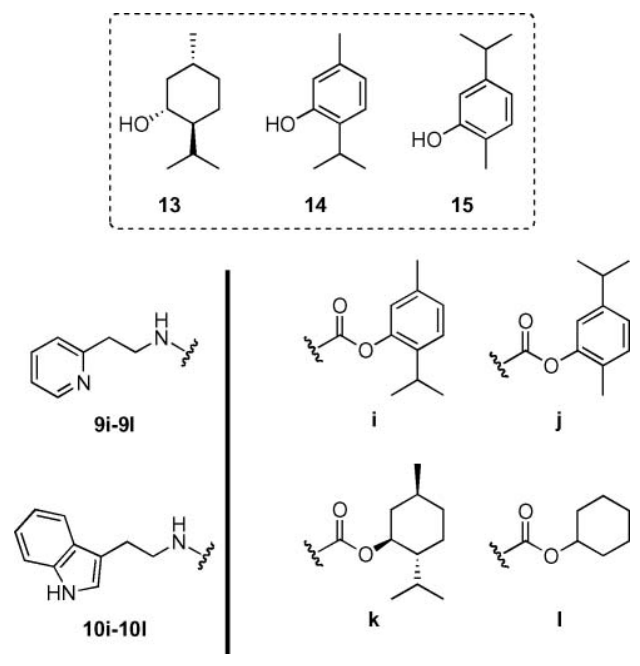

Scheme 3 Analogues of compounds 9a and 10a.

(-)-menthol methyl ether against MRSA and 29213. Interestingly, none of the analogues depicted in Scheme 3 displayed any notable biofilm inhibition activity against either MRSA or 29213 at a $200 \mu \mathrm{M}$ concentration, with the exception of $\mathbf{9 k}$ and $\mathbf{1 0 k}$. These compounds were found to have identical antibiofilm properties as their enantiomers, 9a and 10a. Importantly, both (-)-menthol and (-)-menthol methyl ether were found to be completely inactive.

Lastly, 2d, 8a, 9a, and 10a were preliminarily screened for cytotoxicity. This was assessed using a red blood cell hemolysis assay using difibrinated sheep blood. In each case, the carbamates were found to show no red blood cell lysis up to the highest concentration tested (1.2 mM, see ESI for details $\dagger$ ).

In summary, by targeting analogues of the bacterial metabolite 2d, we have discovered a novel class of biofilm inhibitors based upon a menthyl carbamate scaffold. The culmination of this study resulted in two potent compounds (9a and 10a) that display low micromolar $\mathrm{IC}_{50}$ values for the inhibition of various $S$. aureus biofilms including those from the medically relevant MRSA. This scaffold represents a unique new class of compounds for combating bacterial biofilms. Although they currently lack the ability to disperse preformed biofilms, this disadvantage is offset by their trivial preparation and inherent tunability. It is also noteworthy to mention that high concentrations of antibiofilm agents that have low $\mathrm{IC}_{50}$ values were needed to completely inhibit biofilm formation. This may in part be due to the inherit equilibrium of the biofilm development cycle in that planktonic cells will always continue to form films as long as they are viable. We have recently demonstrated that employing a combination therapy of antibiofilm agents with antibiotics is more effective at completely alleviating the biofilm source since the planktonic cells are constantly being eliminated from the equilibrium. ${ }^{[17]}$ Current efforts in our labs are focused on further tuning this new scaffold as well as marrying this novel menthyl carbamate motif with our 2-aminoimidazole compounds. The results of these studies will be reported in due course.

\section{Acknowledgements}

The authors would like to thank the University of North Carolina General Administration Competitive Research Fund, the V Foundation for a Predoctoral Jimmy V Scholar award (S.A.R.) and the NCSU Office of Undergraduate Research for an undergraduate research fellowship (T.M.).

\section{Notes and references}

1 D. J. Musk and P. J. Hergenrother, Curr. Med. Chem., 2006, 13, 2163.

2 T. B. Rassmussen and M. Givskov, Int. J. Med. Microbiol., 2006, 296, 149.

3 D. Davies, Nat. Rev. Drug Discovery, 2003, 2, 114.

4 R. M. Donlan and J. W. Costerton, Clin. Microbiol. Rev., 2002, 15, 167; P. S. Stewart and J. W. Costerton, Lancet, 2001, 358, 135.

5 J. W. Costerton, P. S. Stewart and E. P. Greenberg, Science, 1999, 284, 1318.

6 J. J. Richards and C. Melander, ChemBioChem, 2009, 10, 2287.

7 G. D. Geske, J. C. O'Neill and H. E. Blackwell, Chem. Soc. Rev., 2008, 37, 1432; M. Manefield, S. Kjelleberg and M. Givskov, Curr. Med. Chem.: Anti-Infect. Agents, 2003, 2, 213.

8 M. Hentzer, H. Wu, J. B. Andersen, K. Riedel, T. B. Rassmussen, N. Bagge, N. Kumar, M. A. Schembri, Z. J. Song, P. Kristoffersen, M. Manefield, J. W. Costerton, S. Molin, L. Eberl, P. Steinberg, S. Kjelleberg, N. Hoiby and M. Givskov, EMBO J., 2003, 22, 3803; H. $\mathrm{Wu}, \mathrm{Z}$. Song, M. Hentzer, J. B. Andersen, S. Molin, M. Givskov and N. Hoiby, J. Antimicrob. Chemother., 2004, 53, 1054.

9 J. F. Hu, E. Garo, M. G. Goering, M. Pasmore, H. D. Yoo, T. Esser, J. Sestrich, P. A. Cremin, G. W. Hough, P. Perrone, Y. S. L. Lee, N. T. Le, M. O'Neil-Johnson, J. W. Costerton and G. R. Eldridge, J. Nat. Prod., 2006, 69, 118; D. C. Ren, R. J. Zuo, A. F. Barrios, L. A. Bedzyk, G. R. Eldridge, M. E. Passmore and T. K. Wood, Appl. Environ. Microbiol., 2005, 71, 4022

10 D. J. Musk, D. A. Banko and P. A. Hergenrother, Chem. Biol., 2005, 12, 789; L. M. Junker and J. Clardy, Antimicrob. Agents Chemother., $2007, \mathbf{5 1}, 3582$.

11 Z. Zeng, L. Qian, L. Cao, H. Tan, Y. Huang, X. Xue, Y. Shen and S. Zhou, Appl. Microbiol. Biotechnol., 2008, 79, 119.

12 R. W. Huigens III, J. J. Richards, G. Parise, T. E. Ballard, W. Zeng, R. Deora and C. Melander, J. Am. Chem. Soc., 2007, 129, 6966; J. J. Richards, T. E. Ballard and C. Melander, Org. Biomol. Chem., 2008, 6, 1356; J. J. Richards, T. E. Ballard, R. W. Huigens III and C. Melander, ChemBio Chem, 2008, 9, 1267; J. J. Richards, R. W. Huigens III, T. E. Ballard, A. Basso, J. Cavanagh and C. Melander, Chem. Commun., 2008, 1698; S. A. Rogers and C. Melander, Angew. Chem., Int. Ed., 2008, 47, 5229; T. E. Ballard, J. J. Richards, A. L. Wolfe and C. Melander, Chem. Eur. J., 2008, 14, 10745.

13 A. Yamada, H. Kitamura, K. Yamaguchi, S. Fukuzawa, C. Kamijima, K. Yaqawa, M. Kuramoto, G. Wang, Y. Fujitani and D. Uemura, Bull. Chem. Soc. Jpn., 1997, 70, 3061.

14 G. A. O'Toole and R. Kolter, Mol. Microbiol., 1998, 30, 295.

15 Z. Schelz, J. Molnar and J. Hohmann, Fitoterapia, 2006, 77, 279; S. K. Filoche, K. Soma and C. H. Sissos, Oral Microbiol. Immunol., 2005, 20, 221; G. Iscan, N. Kirimer, N. Kurkcuoglu, K. Baser and F. Demirci, J. Agric. Food Chem., 2002, 50, 3943; N. Kurita and S. Koike, Agric. Biol. Chem., 1982, 46, 159; B. C. Aridogan, H. Baydar, S. Kaya, M. Demirci, D. Ozbasar and E. Mumcu, Arch. Pharmacal Res., 2002, 25, 860.

16 A. Ben Arfa, S. Combes, L. Preziosi-Belloy, N. Gontard and P. Chalier, Lett. Appl. Microbiol., 2006, 43, 149; A. Sivropoulou, E. Papanikolaou, C. Nikolaou, S. Kokkini, T. Lanaras and M. Arsenakis, J. Agric. Food Chem., 1996, 44, 1202; A. Ultee, R. A. Slump, G. Steging and E. J. Smid, J. Food Protect., 2000, 63, 620.

17 S. A. Rogers, R. W. Huigens, J. Cavanagh and C. Melander, Antimicrob. Agents Chemother., 2010, 54, 2112. 